\title{
Water adsorption isotherms and thermodynamic properties of cassava bagasse
}

\author{
Tiago Carregari Polachini*, Lilian Fachin Leonardo Betiol, José Francisco Lopes-Filho, \\ Javier Telis-Romero
}

Food Engineering and Technology Department, State University of Sao Paulo, São José do Rio Preto, 15054-000 São Paulo, Brazil

\section{A R T I C L E I N F O}

\section{Article history:}

Received 3 December 2015

Received in revised form 22 March 2016

Accepted 25 March 2016

Available online 26 March 2016

\section{Keywords:}

Isotherm of sorption

Entropy

Enthalpy

Isokinetic temperature

Compensation theory

\begin{abstract}
A B S T R A C T
Losses of food industry are generally wet products that must be dried to posterior use and storage. In order to optimize drying processes, the study of isotherms and thermodynamic properties become essential to understand the water sorption mechanisms of cassava bagasse. For this, cassava bagasse was chemically analyzed and had its adsorption isotherms determined in the range of 293.15-353.15 K through the static gravimetric method. The models of GAB, Halsey, Henderson, Oswin and Peleg were fitted, and best adjustments were found for GAB model with $\mathrm{R}^{2}>0.998$ and no pattern distribution of residual plots. Isosteric heat of adsorption and thermodynamic parameters could be determined as a function of moisture content. Compensation theory was confirmed, with linear relationship between enthalpy and entropy and higher values of isokinetic temperature $\left(T_{\mathrm{B}}=395.62 \mathrm{~K}\right)$ than harmonic temperature. Water adsorption was considered driven by enthalpy, clarifying the mechanisms of water vapor sorption in cassava bagasse.
\end{abstract}

(C) 2016 Elsevier B.V. All rights reserved.

\section{Introduction}

Worldwide, several studies have been developed to encourage more efficient applications of byproducts and/or residues from agroindustry. They intend to satisfy environmental and economic concerns by exploring valuable properties in food wastes. The big availability of these raw materials is a result from the large food processing in countries with economy based on agriculture, such as Brazil. It implies in the generation of many kinds of residues, including orange seeds/skin, sugarcane bagasse, coffee pulp/husks, corn stover, peanut shells, grape pomace and cassava bagasse.

Cassava bagasse, specifically, is a residue obtained from the starch extraction process from cassava. It is a fibrous material that still presents approximately $50 \%$ of residual starch in the dry matter. In addition to that, the relative low contents in proteins and ashes reinforce advantages to the application of bioconversion processes in comparison to other residues [1]. The poor conditions of starch extraction plants cause a low efficiency of $25 \%$ based on wet material and consequently an annual amount of almost 2 million tons of wet cassava bagasse, solely in Brazil [2].

\footnotetext{
* Corresponding author.

E-mail addresses: tiagopolachini@terra.com.br, tiagopolachini1@gmail.com (T.C. Polachini).
}

The main problem found during residues management is linked to their handling. The majority of resources should pass through a moisture removal procedure to reduce mass and volume. The dehydration process is one capable way to minimize the storage and transportation costs, besides extending the product shelf life and maintaining the initial characteristics until its destination [3].

The knowledge of water sorption behavior becomes a necessary study to correctly design equipment and drying processes [4]. The use of more accurate methods on the product drying can avoid undesirable effects that may occur on the composition $[5,6]$. Therefore, sorption isotherms appear to provide information about equilibrium moisture content $\left(X_{\text {eq }}\right)$ and water activity $\left(a_{\mathrm{w}}\right)$ by simulating different relative humidity in equilibrium with the product. Sorption properties are useful in drying kinetics studies involving the application of Fick's law for thin layers of wet residues (Eq. (1)), for example:

$$
\frac{\bar{X}-X_{e q}}{X_{0}-X_{e q}}=2 \sum_{n=0}^{\infty} \frac{1}{\gamma_{n}^{2}} \exp \left(\frac{-\gamma_{n}^{2} D t}{l^{2}}\right)
$$

Where $\bar{X}$ is the average moisture content in the product, $X_{0}$ is the initial moisture content, $D$ is the diffusion coefficient, $l$ is the characteristic dimension, $t$ is time and $\gamma_{n}^{2}=(2 n+1) \frac{\pi}{2}$.

The determination and modeling of sorption isotherms in different temperatures gives information about the product conditions 
during storage, since the material stability can be predicted by the availability of water molecules in front of variations in temperature and relative humidity [7]. Moreover, the degree of interactions between water molecules and the residue matrix is as important as the amount of water molecules. It can be measured by the isosteric heat of sorption and many other thermodynamic functions capable of being calculated by isotherms data $[8,9]$.

Thermodynamic parameters are variables responsible by providing insights about the material microstructure, as well as theoretical interpretations for matrix-water interactions [10]. Among them, it could be found the differential enthalpy, differential entropy and free Gibbs energy. Differential enthalpy is valuable for designing equipment involved in water removal processes, once it represents the binding strength of water to the food compounds. On the other hand, differential entropy represents the amount of available sorption sites in a specific energy level [11]. Free Gibbs energy intend to correlate these two functions, corresponding qualitatively to the difference between the total energy available (enthalpy) and the unavailable energy (entropy) [10]. The presence of a linear correlation states that the isokinetic, or enthalpy-entropy, compensation theory exists due to changes in the sorbent-sorbate interaction. The corresponding slope is the isokinetic temperature, representing the temperature at which all reactions in series proceed at the same rate.

Thus, this work intended to characterize the composition of cassava bagasse and present the water sorption properties of cassava bagasse. Among the water sorption properties, adsorption isotherms of powdered cassava bagasse were acquired and modeled in different moisture and temperature conditions. In addition, the application of experimental data of isotherms was used to evaluate thermodynamic properties and the enthalpy-entropy compensation theory, clarifying the water adsorption mechanisms.

\section{Material and methods}

\subsection{Raw material}

The cassava bagasse was obtained directly from a starch extraction industry in northwest of São Paulo state, Brazil. The industrial waste was collected at the entrance of the storage silo and transported in coolers until the Laboratory of Physical Measurements of UNESP (Campus of São José do Rio Preto), where it was stored in plastic bags at $258.15 \mathrm{~K}$ in a freezer. The bagasse was naturally thawed to proceed to the analyses.

In order to carry out the isotherms analyses, cassava waste was dried in a convective tray dryer as reported by Rosa et al. [4] at $323.15 \mathrm{~K}$ by approximately $24 \mathrm{~h}$. The dried waste was then milled using a rotor mill (model MA340, Marconi, Piracicaba, São Paulo, Brazil) equipped with a 30 mesh sieve to obtain a powdered cassava bagasse with particle size less than $595 \mu \mathrm{m}$.

Saturated salt solutions were prepared to obtain an $a_{\mathrm{w}}$ range from 0.046 to 0.873 using lithium bromide ( $\mathrm{LiBr}$ ), lithium chloride $(\mathrm{LiCl})$, lithium iodide ( $\mathrm{LiI})$, potassium acetate $\left(\mathrm{CH}_{3} \mathrm{OOK}\right)$, magnesium chloride $\left(\mathrm{MgCl}_{2}\right)$, magnesium nitrate $\left(\mathrm{Mg}\left(\mathrm{NO}_{3}\right)_{2}\right)$, sodium bromide $(\mathrm{NaBr})$, sodium nitrate $\left(\mathrm{NaNO}_{3}\right)$, sodium chloride $(\mathrm{NaCl})$, potassium bromide $(\mathrm{KBr})$ and potassium chloride $(\mathrm{KCl})$, obtained from Sigma-Aldrich (St. Louis, MO, USA). Table 1 contains the specifications for each salt.

\subsection{Cassava bagasse composition}

Eleven samples of wet fibrous mass of cassava of different production days were acquired from the starch extraction industry. They were characterized with respect to moisture and dry matter in an overnight oven at $378.15 \mathrm{~K}$, ashes in a muffle at $823.15 \mathrm{~K}$ by
Table 1

Sample table with salt specifications.

\begin{tabular}{llc}
\hline Salt & Supplier & Purity (\%) \\
\hline $\mathrm{LiBr}$ & Sigma-Aldrich & $\geq 99.0$ \\
$\mathrm{LiCl}$ & Sigma-Aldrich & $\geq 99.0$ \\
$\mathrm{LiI}$ & Aldrich (Sigma-Aldrich) & 99.0 \\
$\mathrm{CH}_{3} \mathrm{OOK}$ & Sigma-Aldrich & $\geq 99.0$ \\
$\mathrm{MgCl}_{2}$ & Sigma (Sigma-Aldrich) & $\geq 98.0$ \\
$\mathrm{Mg}\left(\mathrm{NO}_{3}\right)_{2}$ & Vetec(Sigma-Aldrich) & 98.0 \\
$\mathrm{NaBr}$ & Sigma-Aldrich & $\geq 99.0$ \\
$\mathrm{NaNO}$ & Sigma-Aldrich & $\geq 99.0$ \\
$\mathrm{NaCl}$ & Sigma-Aldrich & $\geq 99.0$ \\
$\mathrm{KBr}$ & Sigma-Aldrich & $\geq 99.0$ \\
$\mathrm{KCl}-$ & Sigma-Aldrich & $\geq 99.0$ \\
\hline
\end{tabular}

$4 \mathrm{~h}$, fats by Soxhlet extraction, proteins by micro-Kjeldahl method and carbohydrates content by difference. All methods were applied as recommended by AOAC [12].

\subsection{Experimental analysis}

Static gravimetric method was used to determine the isotherms of water sorption along the temperature range [13]. Different equilibrium relative humidites $\left(R H=a_{w} \times 100\right)$ were reached by using glass desiccators with saturated salt solutions of $\mathrm{LiBr}, \mathrm{LiCl}, \mathrm{LiI}$, $\mathrm{CH}_{3} \mathrm{OOK}, \mathrm{MgCl}_{2}, \mathrm{Mg}\left(\mathrm{NO}_{3}\right)_{2}, \mathrm{NaBr}, \mathrm{NaNO}_{3}, \mathrm{NaCl}, \mathrm{KBr}$ and $\mathrm{KCl}$ dissolved into de-ionized water. The temperature of desiccators were set in a controlled temperature chambers type BOD (MA415, Marconi, Piracicaba, Brazil) to maintain temperatures of 293.15, 303.15, $313.15 \mathrm{~K}$ and an oven (MA030, Marconi, Piracicaba, Brazil) for higher temperatures of 323.15, 328.15, 338.15, 343.15, 348.15 and $353.15 \mathrm{~K}$. All experiments were carried out at atmospheric pressure $P_{\mathrm{atm}}=95.47 \mathrm{kPa}$, measured by a barometer. Table 2 contains all values of $a_{\mathrm{w}}$ obtained from the study reported by Labuza [14] for each salt solution versus experimental data of $X_{\text {eq }}$ at each specific temperature.

Approximately $3.0 \mathrm{~g}$ of powdered cassava bagasse in triplicate were weighed in small containers and placed into the desiccator. Samples were previously weighted and had the initial moisture content determined. The weights of the samples were measured every 4 days using an analytical balance (AUW220D, Shimadzu, Japan) until reach constant weight (about 4 weeks). Throughout the weight difference from the initial moisture, the equilibrium moisture content $\left(X_{\mathrm{eq}}\right)$ of each condition was determined.

\subsection{Isotherms modeling}

The mean equilibrium moisture content was plotted against water activities to represent the water adsorption by the nine isotherms obtained. Although isotherms provide information about equilibrium moisture, their modeling also gives water activity values for specific equilibrium moisture content. Using the software OriginPro 8.0 (OriginLab Corporation, Northampton, MA, USA), non-linear regressions were performed to adjust the mathematical models commonly found in literature, such as:

Peleg's model [15]:

$X_{e q}=k_{1} a_{w}^{n_{1}}+k_{2} a_{w}^{n_{2}}$

Halsey's model [16]:

$X_{e q}=\left(-h_{1} \ln \left(a_{w}\right)\right)^{-\frac{1}{h_{2}}}$

Henderson's model [17]:

$X_{e q}=\left(-\frac{1}{H_{1}} \ln \left(1-a_{w}\right)\right)^{\frac{1}{H_{2}}}$ 
Table 2

Experimental data of equilibrium moisture content versus specific water activity in the studied temperatures at atmospheric pressure $\left(P_{\mathrm{atm}}=95.47 \mathrm{kPa}\right)$.

\begin{tabular}{|c|c|c|c|c|c|c|c|c|c|}
\hline \multicolumn{10}{|c|}{ Temperature (Kelvin) } \\
\hline \multicolumn{2}{|l|}{293.15} & \multicolumn{2}{|c|}{303.15} & \multicolumn{2}{|l|}{313.15} & \multicolumn{2}{|l|}{323.15} & \multicolumn{2}{|c|}{328.15} \\
\hline$a_{\mathrm{w}}{ }^{\mathrm{a}}$ & $X_{\mathrm{eq}}$ & $a_{\mathrm{w}}{ }^{\mathrm{a}}$ & $X_{\mathrm{eq}}$ & $a_{\mathrm{w}}{ }^{\mathrm{a}}$ & $X_{\mathrm{eq}}$ & $a_{\mathrm{w}}{ }^{\mathrm{a}}$ & $X_{\text {eq }}$ & $a_{\mathrm{w}}{ }^{\mathrm{a}}$ & $X_{\text {eq }}$ \\
\hline 0.066 & $0.044 \pm 0.001$ & 0.062 & $0.045 \pm 0.002$ & 0.058 & $0.036 \pm 0.000$ & 0.054 & $0.031 \pm 0.001$ & 0.053 & $0.030 \pm 0.001$ \\
\hline 0.118 & $0.052 \pm 0.001$ & 0.111 & $0.051 \pm 0.001$ & 0.105 & $0.043 \pm 0.000$ & 0.100 & $0.037 \pm 0.000$ & 0.098 & $0.035 \pm 0.000$ \\
\hline 0.138 & $0.055 \pm 0.000$ & 0.137 & $0.054 \pm 0.001$ & 0.136 & $0.046 \pm 0.000$ & 0.135 & $0.041 \pm 0.000$ & 0.134 & $0.039 \pm 0.000$ \\
\hline 0.249 & $0.068 \pm 0.001$ & 0.226 & $0.063 \pm 0.001$ & 0.206 & $0.053 \pm 0.000$ & 0.189 & $0.045 \pm 0.001$ & 0.182 & $0.043 \pm 0.000$ \\
\hline 0.329 & $0.077 \pm 0.001$ & 0.323 & $0.073 \pm 0.002$ & 0.318 & $0.064 \pm 0.001$ & 0.314 & $0.055 \pm 0.001$ & 0.311 & $0.051 \pm 0.001$ \\
\hline 0.547 & $0.113 \pm 0.002$ & 0.525 & $0.101 \pm 0.003$ & 0.506 & $0.089 \pm 0.001$ & 0.488 & $0.074 \pm 0.001$ & 0.480 & $0.070 \pm 0.002$ \\
\hline 0.589 & $0.122 \pm 0.003$ & 0.560 & $0.109 \pm 0.004$ & 0.535 & $0.093 \pm 0.000$ & 0.512 & $0.078 \pm 0.000$ & 0.501 & $0.073 \pm 0.000$ \\
\hline 0.752 & $0.187 \pm 0.003$ & 0.731 & $0.165 \pm 0.005$ & 0.712 & $0.144 \pm 0.001$ & 0.694 & $0.119 \pm 0.002$ & 0.686 & $0.112 \pm 0.000$ \\
\hline 0.772 & $0.200 \pm 0.004$ & 0.752 & $0.177 \pm 0.005$ & 0.734 & $0.155 \pm 0.002$ & 0.718 & $0.129 \pm 0.002$ & 0.710 & $0.121 \pm 0.001$ \\
\hline 0.820 & $0.243 \pm 0.003$ & 0.804 & $0.212 \pm 0.004$ & 0.790 & $0.190 \pm 0.005$ & 0.777 & $0.159 \pm 0.002$ & 0.770 & $0.148 \pm 0.001$ \\
\hline 0.873 & $0.306 \pm 0.002$ & 0.837 & $0.243 \pm 0.001$ & 0.806 & $0.203 \pm 0.001$ & 0.777 & $0.159 \pm 0.002$ & 0.764 & $0.143 \pm 0.001$ \\
\hline \multicolumn{2}{|l|}{338.15} & & \multicolumn{2}{|l|}{343.15} & \multicolumn{3}{|l|}{348.15} & \multicolumn{2}{|l|}{353.15} \\
\hline$a_{\mathrm{w}}{ }^{\mathrm{a}}$ & $X_{\mathrm{eq}}$ & & $a_{\mathrm{w}}^{\mathrm{a}}$ & $X_{\mathrm{eq}}$ & $a_{\mathrm{w}}{ }^{\mathrm{a}}$ & $X_{\mathrm{eq}}$ & & $a_{\mathrm{w}}^{\mathrm{a}}$ & $X_{\mathrm{eq}}$ \\
\hline 0.050 & $0.027 \pm 0.000$ & & 0.049 & $0.026 \pm 0.001$ & 0.047 & 0.0 & 0.000 & 0.046 & $0.024 \pm 0.000$ \\
\hline 0.094 & $0.033 \pm 0.001$ & & 0.092 & $0.032 \pm 0.001$ & 0.090 & 0.0 & 0.000 & 0.088 & $0.030 \pm 0.001$ \\
\hline 0.133 & $0.036 \pm 0.000$ & & 0.133 & $0.035 \pm 0.001$ & 0.132 & 0.0 & 0.001 & 0.132 & $0.033 \pm 0.001$ \\
\hline 0.168 & $0.039 \pm 0.001$ & & 0.162 & $0.038 \pm 0.001$ & 0.156 & 0.0 & 0.000 & 0.151 & $0.034 \pm 0.001$ \\
\hline 0.307 & $0.049 \pm 0.000$ & & 0.305 & $0.048 \pm 0.001$ & 0.303 & 0.0 & 0.000 & 0.301 & $0.044 \pm 0.001$ \\
\hline 0.465 & $0.064 \pm 0.000$ & & 0.458 & $0.062 \pm 0.001$ & 0.451 & 0.0 & 0.000 & 0.445 & $0.056 \pm 0.002$ \\
\hline 0.482 & $0.067 \pm 0.000$ & & 0.473 & $0.064 \pm 0.001$ & 0.464 & 0.0 & 0.000 & 0.456 & $0.058 \pm 0.002$ \\
\hline 0.670 & $0.101 \pm 0.002$ & & 0.663 & $0.096 \pm 0.003$ & 0.656 & 0.0 & 0.001 & 0.649 & $0.085 \pm 0.002$ \\
\hline 0.696 & $0.109 \pm 0.002$ & & 0.689 & $0.102 \pm 0.005$ & 0.682 & 0.0 & 0.003 & 0.676 & $0.095 \pm 0.002$ \\
\hline 0.759 & $0.134 \pm 0.001$ & & 0.753 & $0.131 \pm 0.002$ & 0.748 & 0.1 & 0.000 & 0.742 & $0.115 \pm 0.002$ \\
\hline 0.739 & $0.125 \pm 0.000$ & & 0.727 & $0.118 \pm 0.003$ & 0.716 & 0.1 & 0.000 & 0.705 & $0.103 \pm 0.002$ \\
\hline
\end{tabular}

a Data obtained from Labuza [14]. $a_{\mathrm{w}}$-water activity; $X_{\text {eq }}-$ equilibrium moisture content.

Oswin's model [18]:

$X_{e q}=M\left(\frac{a_{w}}{1-a_{w}}\right)^{N}$

Guggenheim, Anderson and de Boer-GAB model [19], which has been widely applied in foodstuffs:

$X_{e q}=\frac{X_{m} C k a_{w}}{\left(1-K a_{w}\right)\left(1+(C-1) K a_{w}\right)}$

Where $k_{1}, k_{2}, n_{1}, n_{2}, h_{1}, h_{2}, H_{1}, H_{2}, M, N, k, C$ and $X_{\mathrm{m}}$ are constants of de models.

The fit accuracy for each model was evaluated based on the adjusted coefficient of determination $\left(R_{a d j}^{2}\right)$, the root mean square error (RMSE) and residual distribution. Adjustments with low $R_{a d j}^{2}$ and high RMSE and/or clear pattern in residual plots should be discarded [20].

\subsection{Thermodynamic approach}

The temperature dependence of the isotherm can be represented by the net isosteric heat of adsorption, which assumes to be invariant with temperature. Plotting $\ln \left(a_{w}\right)$ as a function of $(1 / T)$ in a fixed equilibrium moisture, the net isosteric heat of sorption or enthalpy of sorption $\left(q_{s t}\right)$ can be determined by the slope from Clausius-Clapeyron equation (Eq. (7)). The application of this method requires the measurement of adsorption isotherms at least three temperatures [21]. In addition, the $q_{s t}$ is also defined as the difference between integral heat of sorption $\left(Q_{s t}\right)$ and the heat of vaporization of water $(\lambda)[10]$ :

$\left.\frac{\partial\left(\ln a_{w}\right)}{\partial(1 / T)}\right|_{X_{e q}}=-\frac{Q_{s t}-\lambda}{R}=-\frac{q_{s t}}{R}$
After obtained values of $q_{\mathrm{st}}$, it is common to express the net isosteric heat of sorption as a function of equilibrium moisture content by Riedel's equation:

$q_{s t}=C_{r} \exp \left(-B_{r} X_{e q}\right)$

Since thermodynamic properties can express the behavior of water adsorption, Eq. (8) represents the variation in molar differential entropy of adsorption $(\Delta S)$ by Gibbs-Helmholtz equation:

$\Delta S=\frac{\Delta H-\Delta G}{T}$

Considering that Gibbs free energy is calculated as:

$\Delta G=R T \ln a_{w}$

Combining Eq. (9) and Eq. (8), the change in Gibbs free energy is expressed by variations on both enthalpy and entropy, resulting in Eq. (11):

$\ln a_{w}=\frac{\Delta H}{R T}-\frac{\Delta S}{R}$

In this way, enthalpy of adsorption and entropy can be calculated from Eq. (11) by same procedure as described for net isosteric heat of sorption, extracting values of slope $(\Delta H / R)$ and the linear coefficient $(\Delta S / R)$.

Correlating the obtained values of $\Delta H$ versus $\Delta S$ for adsorption data, a linear tendency is expected to confirm the compensation theory for adsorption [22]:

$\Delta H=T_{B}(\Delta S)+\Delta G_{B}$

In this relation, $T_{\mathrm{B}}$ is the isokinetic temperature and represents the temperature at which all reactions in the series proceed at the same rate. 
Another test for validating the compensation theory is comparing the isokinetic temperature with the harmonic mean temperature $T_{\mathrm{hm}}[23,24]$, that is defined as:

$T_{h m}=\frac{n}{\sum_{i=1}^{n}(1 / T)}$

For a (1- $\alpha) 100 \%$ confidence interval, $T_{\mathrm{B}}$ may be calculated from:

$T_{B}=T_{B} \pm t_{m-2, \alpha / 2} \sqrt{\operatorname{Var}\left(T_{B}\right)}$

Where

$T_{B}=\frac{\sum(\Delta H-\overline{\Delta H})(\Delta S-\overline{\Delta S})}{\sum(\Delta S-\overline{\Delta S})^{2}}$

$\operatorname{Var}\left(T_{B}\right)=\frac{\sum\left(\Delta H-\overline{\Delta G}_{B}-T_{B} \Delta S\right)^{2}}{(m-2) \sum(\Delta S-\overline{\Delta S})^{2}}$

And $m$ is the number of $(\Delta H, \Delta S)$ data pairs, $\overline{\Delta H}$ the average enthalpy, and $\overline{\Delta S}$ the average entropy.

\section{Results and discussion}

\subsection{Cassava bagasse composition}

Cassava bagasse composition was chemically determined based on analyses of eleven samples collected in eleven different days of starch production. It allowed the evaluation of the changes on waste composition to provide significant data.

By composition data presented in Table 3, the moisture content of cassava bagasse showed high values ranging from 81.08 to $85.92 \%$ (w. b.), which confirms the necessity of drying process to remove water and extend the storage for longer periods until its destination. Relatively low contents of proteins, ashes and fats were evidenced, and their variations could be related to the use of different cassava varieties and to the poor conditions found in cassava processing [1]. The dry matter content was similar to those encountered by Teixeira et al. [25] (17.5\%) and Cereda [26] (14.88\%) for cassava bagasse. It was evidenced that dry matter is mainly composed by carbohydrates, reaching a value of $82.85 \%$ (d. b.). Many authors have highlighted great contents $(>50 \%)$ of starch in this dry matter $[1,26,27]$. Starch is a compound with valuable properties and can be used in various processes. Its composition of glucose monomers bounded by $\alpha-(1,4)$ linkage emphasizes the capacity of release fermentable matter as substrate for microorganisms and for bioethanol production.

\subsection{Adsorption isotherms}

Values of equilibrium moisture content $\left(X_{\mathrm{eq}}\right)$ and water activity $\left(a_{\mathrm{w}}\right)$ were obtained in the range of $0.024-0.269 \mathrm{~g} / \mathrm{g}$ dried matter and 0.046 and 0.873 , respectively. Equilibrium moisture content decreased as the temperature increased at fixed water activities, while an increase was observed in $X_{\text {eq }}$ with increasing water activity values at a stablished temperature. Data pairs $\left(X_{\mathrm{eq}}, a_{\mathrm{w}}\right)$ were plotted and fitted to Eqs. (2)-(6) for all temperatures. By the graph in Fig. 1, curves shape seemed to follow a sigmoid behavior, typical of type II isotherms [28]. This kind of isotherm can be classified into three regions: the first one correspond to the monolayer moisture strongly bounded into the product matrix; the second is almost linear, corresponding to the multilayered water; and the third region is related to the free water available for chemical reactions [29].

After evaluation of fitting parameters to the experimental data disposed in Table 4, Henderson model demonstrated the lower $R_{a d j}^{2}$

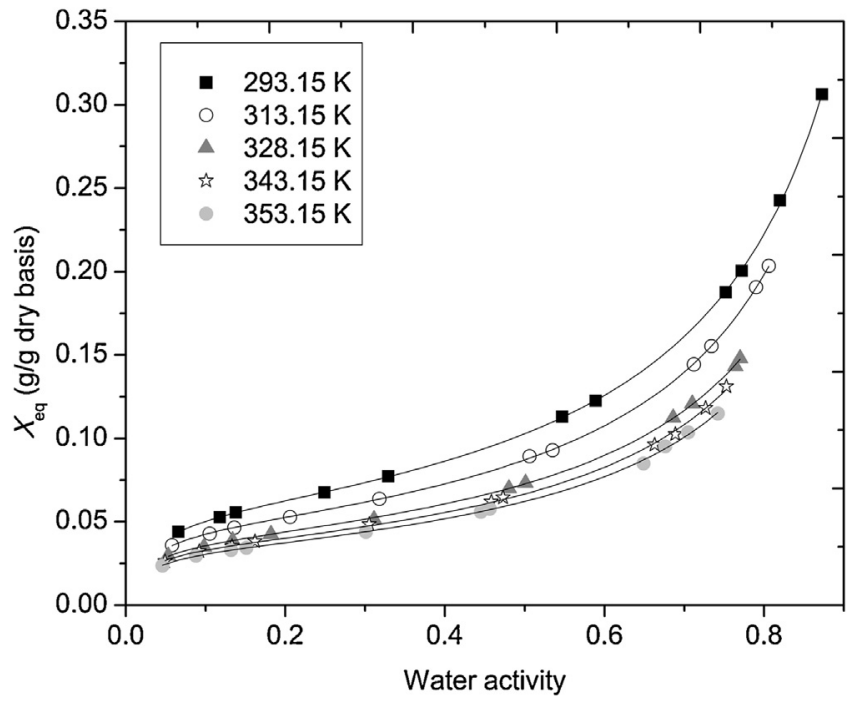

Fig. 1. Adsorption isotherms fitted to $G A B$ equation of powdered cassava bagasse in intermediate temperatures.

followed by Oswin and Halsey equation. Peleg's model indicated good accuracy of experimental data, but the quantity of parameters implied in lower $R_{a d j}^{2}$ and higher RMSE than GAB equation. In this way, the GAB model (Eq. (5)) showed to be the best form to represent adsorption isotherms, as shown in Fig. 1 for some intermediate temperatures. Besides the adjustments to GAB equation had greater $R_{a d j}^{2}$ and lower RMSE, no pattern distribution in the residual plots was verified (Fig. 2). According to Al-Muhtaseb et al. [9] and Telis et al. [30], GAB model is considered the most versatile model available in literature for sorption isotherms. The same authors concluded that GAB model represents adequately the sorption isotherms of starchy products, such as potato and wheat starch, and lignocellulosic materials such as persimmon skin.

Analyzing GAB parameters $\left(C, k\right.$ and $\left.X_{\mathrm{m}}\right)$, it could be seen a similarity to those reported for bagasse dehydrate yacon [31], dried pulp of mango [32] and even composites of cassava bagasse [33]. As verified by Blahovec [34], values of $C$ and $k$ are in accordance with type II isotherms from Brunauer classification. In this classification, $k$ has to be higher than 0 and less than 1 , while $C$ values should be higher than 2 . Although lower values of $C$ were expected as temperature increases [34], a not clear tendency could be verified for the whole range of temperature probably due to the regression methods used during the adjustments [35]. With respect to $k$, it is common to find higher values for dried material when compared to fresh products [36]. It confirms the tendency reported in this study, which observed increasing values of $k$ as temperature gets higher and, consequently, equilibrium moisture content and monolayer moisture content decrease. Monolayer moisture content $\left(X_{\mathrm{m}}\right)$ assumes the role of the first shell of water that covers the sorbent surface. Above this value of moisture, there are the multilayers of water, representing less interaction with the food matrix than monolayer moisture [35]. In addition, $X_{\mathrm{m}}$ seemed to present highly dependence on temperature, where lower values were found when the temperature increases. It could be attributed to a reduction in active sorption sites due to changes in both physical and chemical aspects [37]. Specially in the case of adsorption phenomenon, Van den Berg [38] proposed that the few available sites for sorption have a greater binding energy on comparison to desorption isotherms. As known that cassava bagasse is very rich in starch, the decrease in monolayer moisture is related to the degree of hydrogen bonding when temperature increases, reducing the availability of active sites for water binding [39]. 
Table 3

Chemical composition of wet cassava bagasse composition obtained in 11 different days.

\begin{tabular}{|c|c|c|c|c|c|c|}
\hline Sample & Moisture (\%-w. b.) & Dry matter (\%-w. b.) & Proteins (\%-d. b.) & Ashes (\%-d. b.) & Fats (\%-d. b.) & Carbohydrates (\%-d. b. \\
\hline 1 & 85.08 & 14.92 & 11.60 & 15.80 & 7.94 & 64.67 \\
\hline 2 & 85.92 & 14.09 & 11.19 & 14.73 & 7.69 & 66.39 \\
\hline 3 & 81.58 & 18.42 & 8.39 & 10.44 & 5.71 & 75.46 \\
\hline 4 & 81.08 & 18.92 & 7.02 & 6.28 & 3.85 & 82.85 \\
\hline 5 & 85.08 & 14.92 & 11.60 & 15.80 & 7.94 & 64.67 \\
\hline 6 & 82.58 & 17.42 & 10.29 & 11.37 & 6.39 & 71.96 \\
\hline 7 & 82.58 & 17.42 & 6.38 & 7.58 & 4.24 & 81.80 \\
\hline 8 & 83.92 & 16.08 & 7.85 & 9.59 & 5.87 & 76.69 \\
\hline 9 & 82.90 & 17.10 & 10.69 & 13.05 & 6.32 & 69.94 \\
\hline 10 & 85.04 & 14.96 & 10.50 & 10.18 & 6.79 & 72.53 \\
\hline 11 & 81.79 & 18.22 & 8.34 & 12.35 & 5.54 & 73.77 \\
\hline Mean & 83.41 & 16.59 & 9.44 & 11.56 & 6.21 & 72.79 \\
\hline Standard deviation & 1.67 & 1.67 & 1.89 & 3.16 & 1.37 & 6.22 \\
\hline
\end{tabular}

w. b.-wet basis based on mass.

d. b.-dry basis based on mass.

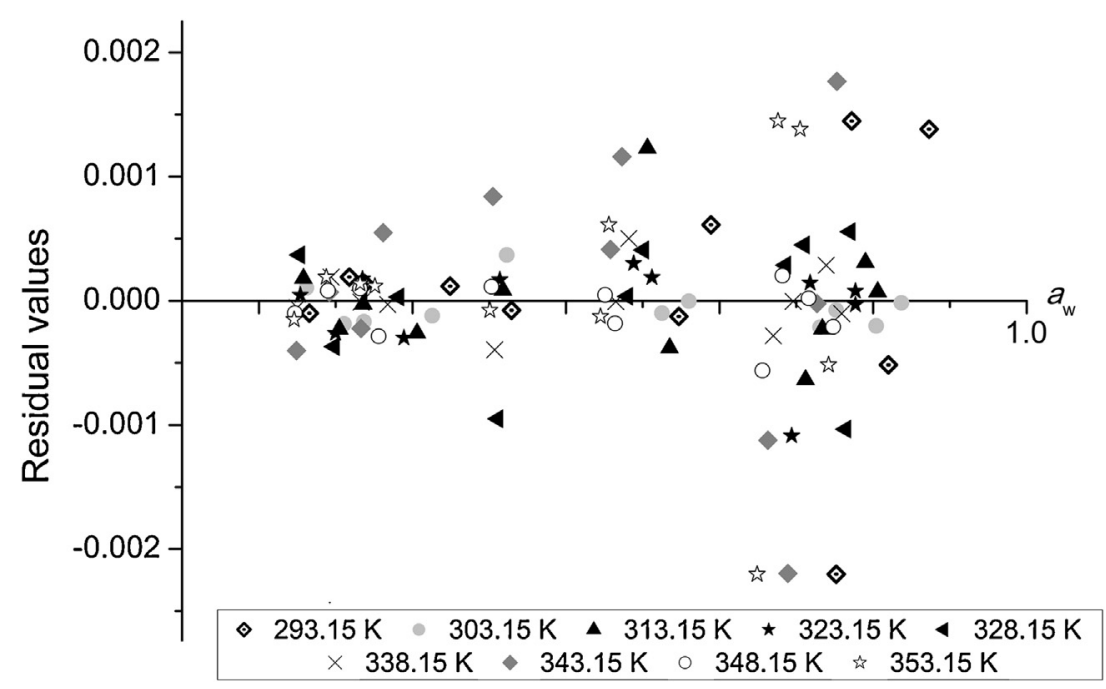

Fig. 2. Residual plot distributions for GAB equation in all temperatures.

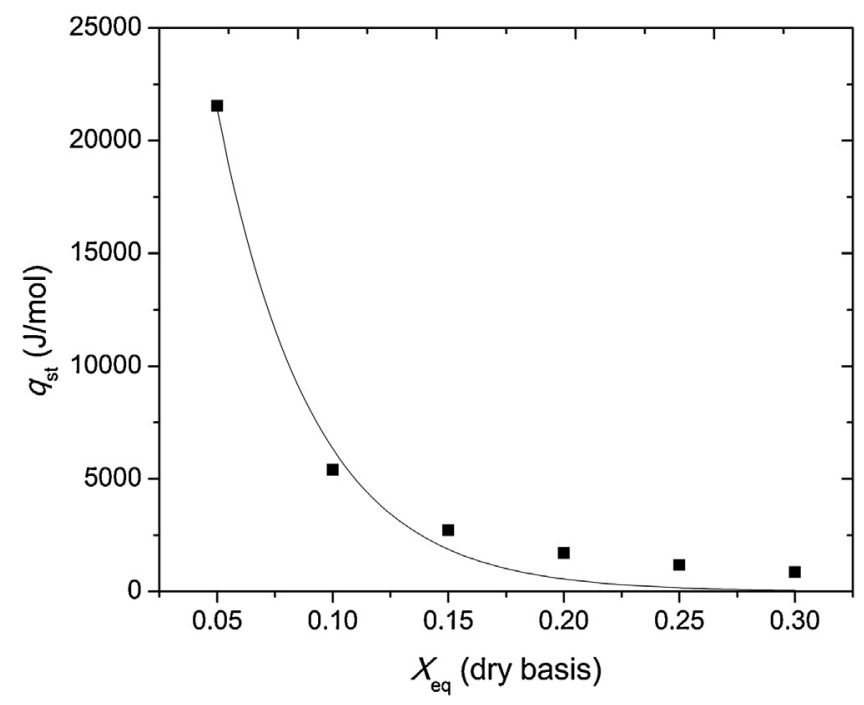

Fig. 3. Net isosteric heat of adsorption for powdered cassava bagasse as a function of equilibrium moisture content.

\subsection{Thermodynamic properties}

Water activities were determined for fixed equilibrium moisture content by GAB fitted equations in the different temperatures.
It allowed to calculate the isosteric heat of adsorption $\left(q_{\mathrm{st}}\right)$ by Eq. (7), which were plotted against equilibrium moisture content and fitted to Eq. (8) (Fig. 3). Riedel's equation could express $q_{\text {st }}$ values as a function of moisture content with more than $98.2 \%$ of accuracy, with $C_{\mathrm{r}}=72264.02 \mathrm{~J} / \mathrm{mol}$ and $B_{\mathrm{r}}=24.35$. The higher values are encountered at lower moisture content, when water is strongly bonded into the material structure of cellulose fibers and starch granules. But, a rapid decrease occurs in the isosteric heat of sorption when moisture content begins to increase due to the adsorption of water molecules in the multilayer. The same exponential decrease was also observed for different products with great contents of sugar and starch such as grapes and potatoes, respectively [40]. Focusing on the thermodynamic approach, the behavior of water adsorption can be evaluated according to the differential enthalpy and entropy by Eq. (7) in a range of $X_{\text {eq }}$ from 0.05 to 0.30 . As expected, the change in enthalpy was represented by negative values ranging from -21.55 to $-0.85 \mathrm{~kJ} / \mathrm{mol}$ while entropy presented positive values ranging from 53.88 to $1.74 \mathrm{~J} / \mathrm{mol}$. Both, in modulus, tend to lower values as the moisture content increases (Fig. 4) and followed the same trend as hydrolyzed starch [41] and persimmon skin and pulp [30]. The enthalpy, similarly as isosteric heat of sorption, illustrates the required energy to do a useful work. At higher moisture contents, less energy is needed to remove a same amount of water in more dried sample due to the fewer available binding sites to promote sorption [42]. On the other hand, entropy represents lost work or energy not available to perform a determined process. Samples with low moisture content present higher val- 
Table 4

Parameters of the proposed models fitted to adsorption data.

\begin{tabular}{llllll}
\hline Temperature $(\mathrm{K})$ & \multicolumn{6}{l}{$\mathrm{GAB}$} & & & \\
\cline { 2 - 6 } & $X_{\mathrm{m}}$ & $C$ & $k$ & $R_{\text {adj }}^{2}$ & RMSE \\
\hline 293.15 & 0.0561 & 41.1140 & 0.9370 & 0.9999 & 0.0007 \\
303.15 & 0.0524 & 64.3790 & 0.9382 & 0.9999 & 0.0002 \\
313.15 & 0.0464 & 45.5290 & 0.9592 & 0.9999 & 0.0005 \\
323.15 & 0.0403 & 46.7159 & 0.9627 & 0.9999 & 0.0004 \\
328.15 & 0.0386 & 47.4302 & 0.9611 & 0.9998 & 0.0005 \\
338.15 & 0.0365 & 46.0861 & 0.9619 & 0.9999 & 0.0002 \\
343.15 & 0.0349 & 53.3952 & 0.9722 & 0.9989 & 0.0010 \\
348.15 & 0.0340 & 45.4132 & 0.9645 & 0.9999 & 0.0001 \\
353.15 & 0.0327 & 49.5185 & 0.9685 & 0.9989 & 0.0009
\end{tabular}

\begin{tabular}{lllllll} 
& \multicolumn{7}{l}{ Peleg } & \multicolumn{1}{l}{} \\
\cline { 2 - 7 }$k_{1}$ & $n_{1}$ & $k_{2}$ & $n_{2}$ & $R_{\text {adj }}^{2}$ & $R M S E$ \\
\hline 293.15 & 0.4190 & 6.0511 & 0.1278 & 0.4205 & 0.9989 & 0.0023 \\
303.15 & 0.3491 & 5.1683 & 0.1082 & 0.3398 & 0.9989 & 0.0019 \\
313.15 & 0.0994 & 0.3759 & 0.3396 & 5.2030 & 0.9991 & 0.0015 \\
323.15 & 0.2821 & 4.9145 & 0.0840 & 0.3599 & 0.9993 & 0.0010 \\
328.15 & 0.2410 & 4.3305 & 0.0749 & 0.3254 & 0.9993 & 0.0009 \\
338.15 & 0.0728 & 0.3398 & 0.2311 & 4.4810 & 0.9995 & 0.0007 \\
343.15 & 0.0771 & 0.3732 & 0.3042 & 5.6677 & 0.9988 & 0.0010 \\
348.15 & 0.0682 & 0.3430 & 0.2178 & 4.5169 & 0.9997 & 0.0005 \\
353.15 & 0.2147 & 4.5018 & 0.0652 & 0.3319 & 0.9986 & 0.0010
\end{tabular}

\begin{tabular}{|c|c|c|c|c|}
\hline & \multicolumn{4}{|l|}{ Halsey } \\
\hline & $h_{1}$ & $h_{2}$ & $R_{a d j}^{2}$ & $\overline{R M S E}$ \\
\hline 293.15 & 44.6828 & 1.5254 & 0.9994 & 0.0020 \\
\hline 303.15 & 51.8888 & 1.5595 & 0.9983 & 0.0026 \\
\hline 313.15 & 48.2298 & 1.4585 & 0.9983 & 0.0023 \\
\hline 323.15 & 59.6340 & 1.4640 & 0.9980 & 0.0020 \\
\hline 328.15 & 65.7929 & 1.4767 & 0.9982 & 0.0017 \\
\hline 338.15 & 72.7467 & 1.4827 & 0.9981 & 0.0015 \\
\hline 343.15 & 74.9732 & 1.4811 & 0.9957 & 0.0022 \\
\hline 348.15 & 80.8784 & 1.4828 & 0.9980 & 0.0014 \\
\hline \multirow[t]{3}{*}{353.15} & 85.6269 & 1.4885 & 0.9964 & 0.0018 \\
\hline & \multicolumn{4}{|c|}{ Henderson } \\
\hline & $H_{1}$ & $\mathrm{H}_{2}$ & $R_{a d j}^{2}$ & RMSE \\
\hline 293.15 & 10.4505 & 1.2655 & 0.9485 & 0.0181 \\
\hline 303.15 & 16.5886 & 1.4636 & 0.9438 & 0.0151 \\
\hline 313.15 & 18.1248 & 1.4335 & 0.9503 & 0.0124 \\
\hline 323.15 & 27.3243 & 1.5210 & 0.9511 & 0.0098 \\
\hline 328.15 & 33.2394 & 1.5708 & 0.9521 & 0.0088 \\
\hline 338.15 & 43.7914 & 1.6405 & 0.9528 & 0.0077 \\
\hline 343.15 & 49.7869 & 1.6739 & 0.9463 & 0.0078 \\
\hline 348.15 & 57.3988 & 1.6953 & 0.9530 & 0.0068 \\
\hline \multirow[t]{3}{*}{353.15} & 66.7030 & 1.7318 & 0.9491 & 0.0067 \\
\hline & \multicolumn{4}{|l|}{ Oswin } \\
\hline & $\bar{M}$ & $N$ & $R_{a d j}^{2}$ & $\overline{R M S E}$ \\
\hline 293.15 & 0.1115 & 0.5049 & 0.9864 & 0.0093 \\
\hline 303.15 & 0.1075 & 0.4695 & 0.9802 & 0.0089 \\
\hline 313.15 & 0.0967 & 0.4909 & 0.9814 & 0.0076 \\
\hline 323.15 & 0.0844 & 0.4763 & 0.9804 & 0.0062 \\
\hline 328.15 & 0.0806 & 0.4667 & 0.9804 & 0.0056 \\
\hline 338.15 & 0.0759 & 0.4555 & 0.9802 & 0.0050 \\
\hline 343.15 & 0.0741 & 0.4511 & 0.9753 & 0.0053 \\
\hline 348.15 & 0.0705 & 0.4476 & 0.9797 & 0.0045 \\
\hline 353.15 & 0.0685 & 0.4419 & 0.9766 & 0.0045 \\
\hline
\end{tabular}

$X_{\mathrm{m}}$ (monolayer moisture content), $C$ and $k$ (constants related to the energy of interaction between the first and multilayers water molecules)-parameters of GAB model; $k_{1}, k_{2}, n_{1}, n_{2}$-parameters of Peleg model; $h_{1}, h_{2}$-parameters of Halsey model; $H_{1}, H_{2}$-parameters of Henderson model; $M, N$-parameters of Oswin model; $R_{\text {adj }}^{2}$-adjusted correlation coefficient; RSME-root mean square error.

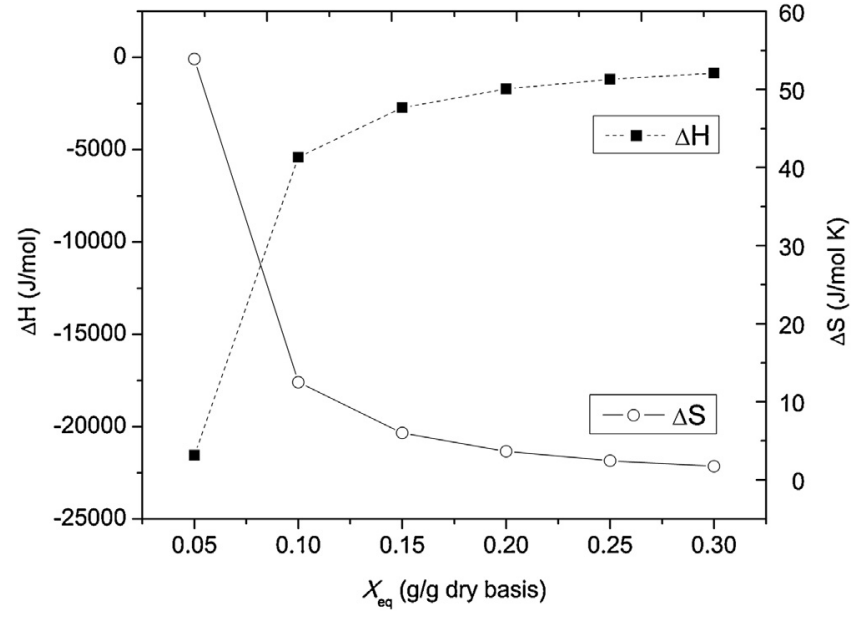

Fig. 4. Change in enthalpy and entropy as a function of equilibrium moisture contents.

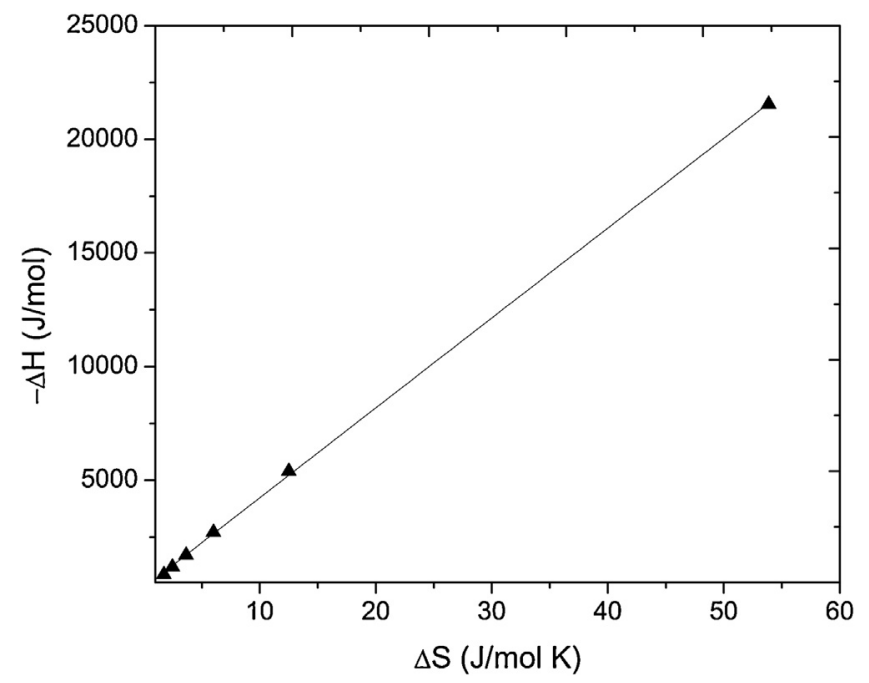

Fig. 5. Linear regression of differential enthalpy versus differential entropy values

ues of entropy, indicating that more energy (or enthalpy values) is necessary to remove the water molecules in that conditions [10].

One first important requirement to confirm the enthalpyentropy compensation theory, is the presence of a linear relationship between enthalpy and entropy. The linear tendency observed in Fig. 5, with $R_{a d j}^{2}>0.999$, means that the change in enthalpy is accompanied by simultaneous changes in both entropy and Gibbs free energy. In turn, Gibbs free energy tends towards to assume values around zero as the moisture content increases, indicating that dehydration process is more spontaneous when powdered cassava bagasse is adsorbed by multilayers of water molecules.

Using the same graph in Fig. 5 and value of $\operatorname{Var}\left(T_{\mathrm{B}}\right)$, the temperature at which all reaction in series occur at the same rate $\left(T_{\mathrm{B}}\right)$ was stablished at $395.62 \pm 6.64 \mathrm{~K}$ [30]. The presence of higher values of $T_{\mathrm{B}}$ (above $300 \mathrm{~K}$ ) were characteristics observed for products with high sugar or starch content such as potatoes, prune and apricot $[43,44]$. If this temperature is different from harmonic temperature $\left(T_{\mathrm{hm}}\right)$, the second requirement to confirm a linear chemical compensation pattern is evidenced $[23,24]$. Applying Eq. (13), $T_{\mathrm{hm}}$ resulted in a value of $325.84 \mathrm{~K}$, which is significant lower than isokinetic temperature $\left(T_{\mathrm{B}}\right)$ with $95 \%$ of confidence. Besides proving the isokinetic compensation theory, the study reported by Leffler 
[45] allowed to assume the water adsorption as an enthalpy driven process since $T_{\mathrm{B}}>T_{\mathrm{hm}}$.

\section{Conclusions}

The water sorption behavior of cassava bagasse was evaluated in order to optimize drying kinetics and minimize the energy expenses involved in dehydration processes. Thus, adsorption isotherms of powdered cassava bagasse were studied in temperatures from 293.15 to $353.15 \mathrm{~K}$, presenting increasing values of equilibrium moisture content when relative humidity increased and temperature decreased. These data could be well-fitted to the GAB model with great accuracy $\left(R_{a d j}^{2}>0.998\right.$ and $\left.R M S E<0.001\right)$, making available data of monolayer moisture content from 0.056 to 0.033 . Thermodynamic properties were determined as a function of equilibrium moisture content. In an interval of $X_{\text {eq }}$ of $0.05-0.30$, enthalpy and entropy values ranged from -21.55 to $-0.85 \mathrm{~kJ} / \mathrm{mol}$ and from 53.88 to $1.74 \mathrm{~J} / \mathrm{mol} \mathrm{K}$, respectively. The linear relationship between them showed that lower energy is necessary to remove a certain amount of water at higher moisture contents, which is associated to the decrease in the number of available sites to sorption followed by a reduction of interactions between cassava bagasse matrix and water molecules in the multilayer. This phenomenon makes the water removal process "more spontaneous" when cassava bagasse presents higher moisture contents. It was found a higher value of $395.62 \pm 6.64 \mathrm{~K}$ for isokinetic temperature than for harmonic temperature $(325.84 \mathrm{~K})$, confirming the consideration of enthalpy driven process to water adsorption of cassava bagasse.

\section{Acknowledgements}

The authors are grateful to the National Counsel of Technological and Scientific Development (Grant: 306584/2013-1) and Sao Paulo Research Foundation (Grant: 2013/17497-5) for the financial support.

\section{References}

[1] A. Pandey, C.R. Soccol, P. Nigam, V.T. Soccol, L.P.S. Vandenberghe, R. Mohan, Biotechnological potential of agro-industrial residues. II: cassava bagasse, Bioresour. Technol. 74 (2000) 81-87.

[2] F.A. Fiorda, M.S.S. Soares Jr., F.A. Silva, L.R.F. Souto, M.V.E. Grossmann, Farinha de bagaço de mandioca: aproveitamento de subproduto e comparação com fécula de mandioca, Pesquisa Agropecuária Tropical 43 (2013) 408-416.

[3] A. Vega-Gálvez, M. Miranda, L.P. Díaz, L. Lopez, K. Rodriguez, K. Di Scala, Effective moisture diffusivity determination and mathematical modelling of the drying curves of the olive-waste cake, Bioresour. Technol. 101 (2010) $7265-7270$

[4] D.P. Rosa, D. Cantú-Lozano, G. Luna-Solano, T.C. Polachini, J. Telis-Romero, Mathematical modeling of orange seed drying kinects, Ciência e Agrotecnologia 39 (2015) 291-300.

[5] J. Viganó, E. Azuara, V.R.N. Telis, C.I. Beristain, M. Jiménez, J. Telis-Romero, Role of enthalpy and entropy in moisture sorption behavior of pineapple pulp powder produced by different drying methods, Thermochim. Acta 528 (2012) 63-71.

[6] G.L. Castiglioni, F.A. Silva, M. Caliari, M.S. Soares Júnior, Modelagem matemática do processo de secagem da massa fibrosa de mandioca, Revista Brasileira de Engenharia Agrícola e Ambiental 17 (2013) 987-994.

[7] V.R. Sinija, H.N. Mishra, Moisture sorption isotherms and heat of sorption of instant (soluble) green tea powder and green tea granules, J. Food Eng. 86 (2008) 494-500.

[8] A. Jamali, M. Kouhila, L. Ait Mohamed, J.T. Jaouhari, A. Idlimam, N. Abdenouri, Sorption isotherms of Chenopodium ambrosioides leaves at three temperatures, J. Food Eng. 72 (2006) 77-84.

[9] A.H. Al-Muhtaseb, W.A.M. McMinn, T.R.A. Magee, Water sorption isotherms of starch powders: part 1: mathematical description of experimental data, J. Food Eng. 61 (2004) 297-307.

[10] S.S.H. Rizvi, Thermodynamic properties of foods in dehydration, in: M.A. Rao, S.S.H. Rizvi (Eds.), Engineering of Foods, Academic Press, New York, 1995.

[11] R. Moreira, F. Chenlo, M.D. Torres, N. Vallejo, Thermodynamic analysis of experimental sorption isotherms of loquat and quince fruits, J. Food Eng. 88 (2008) 514-521

[12] AOAC, Official Methods of Analysis, 18th ed., 2005, Association of Official Analytical Chemists; Washington, D. C.
[13] R.J. Jowitt, F. Escher, B. Hallsrom, H. Meffert, W. Spiess, G. Vos, Physical Properties of Foods, Applied Science Publishers, London, 1983.

[14] T. Labuza, Creation of moisture sorption isotherms for hygroscopic materials. Sorption isotherm methods, International Symposium on Humidity and Moisture (1963).

[15] M. Peleg, Assessment of a semi-empirical four parameter general model for sigmoid moisture sorption isotherms, J. Food Process Eng. 16 (1993) 21-37.

[16] G. Halsey, Physical adsorption on non-uniform surfaces, J. Chem. Phys. 16 (1948) 931-937.

[17] R. Boquet, J. Chirife, H.A. Iglesias, Equations for fitting water sorption isotherms of foods, Int. J. Food Sci. Technol. 13 (1978) 319-327.

[18] C.R. Oswin, The kinetics of package life. III. The isotherm, J. Soc. Chem. Ind. 65 (1946) 419-421.

[19] C.J. Lomauro, A.S. Bakshi, T.P. Labuza, Evaluation of food moisture sorption isotherm equations. Part I: fruit, vegetable and meat products, Lebensmittel-Wissenschaft und-Technologie 18 (1985) 111-117.

[20] J.V. García-Pérez, J.A. Cárcel, G. Clemente, A. Mulet, Water sorption isotherms for lemon peel at different temperatures and isosteric heats, LWT - Food Sci. Technol. 41 (2008) 18-25.

[21] G.S. Mittal, W.R. Usborne, Moisture isotherms for uncooked meat emulsions of different composition, J. Food Sci. 50 (1985) 1576-1579.

[22] P.S. Madamba, R.H. Driscoll, K.A. Buckle, Enthalpy-entropy compensation models for sorption and browning of garlic, J. Food Eng. 28 (1996) 109-119.

[23] R.R. Krug, W.G. Hunter, R.A. Grieger, Enthalpy-entropy compensation. 1. Some fundamental statistical problems associated with the analysis of van't Hoff and Arrhenius data, J. Phys. Chem. 80 (1976) 2335-2341.

[24] R.R. Krug, W.G. Hunter, R.A. Grieger, Enthalpy-entropy compensation. 2. Separation of the chemical from the statistical effect, J. Phys. Chem. 80 (1976) 2341-2351.

[25] E.M. Teixeira, D. Pasquini, A.A.S. Curvelo, E. Corradini, M.N. Belgacem, A. Dufresne, Cassava bagasse cellulose nanofibrils reinforced thermoplastic cassava starch, Carbohydr. Polym. 78 (2009) 422-431.

[26] M.P. Cereda, Caracterização de resíduos da industrialização da mandioca, in: M.P. Cereda (Ed.), Resíduos da industrialização da mandioca no Brasil, Paulicéia, São Paulo, 1994, pp. 11-50.

[27] F.S. Carta, C.R. Soccol, L.P. Ramos, J.D. Fontana, Production of fumaric acid by fermentation of enzymatic hydrolysates derived from cassava bagasse, Bioresour. Technol. 68 (1999) 23-28.

[28] S. Brunauer, L.S. Deming, W.E. Deming, E. Teller, On a theory of the van der Waals adsorption of gases, J. Am. Chem. Soc. 62 (1940) 1723-1732.

[29] M. Mathlouthi, Water content water activity, water structure and the stability of foodstuffs, Food Control 12 (2001) 409-417.

[30] V.R.N. Telis, A.L. Gabas, F.C. Menegalli, J. Telis-Romero, Water sorption thermodynamic properties applied to persimmon skin and pulp, Thermochim. Acta 343 (2000) 49-56.

[31] C.C. Lago, C.P.Z. Noreña, Thermodynamic analysis of sorption isotherms of dehydrated yacon (Smallanthus sonchifolius) bagasse, Food Biosci. 12 (2015) 26-33.

[32] C.S. Paglarini, F.S. Silva, A.G. Porto, D. Piasson, P. Santos, Histerese das isotermas de sorção da polpa de manga (Mangifera indica L.) variedade manteiga, Revista Brasileira de Engenharia Agrícola e Ambiental 17 (2013) 299-305.

[33] K.N. Matsui, F.D.S. Larotonda, A.T.N. Pires, J.B. Laurindo, Moisture isotherms of cassava bagasse composites impregnated with cassava starch acetate solutions, Alimentos e Nutrição 14 (2003) 137-140.

[34] J. Blahovec, Sorption isotherms in materials of biological origin mathematical and physical approach, J. Food Eng. 65 (2004) 489-495.

[35] E.J. Quirijns, A.J.B. Van Boxtel, W.K.P. Van Loon, G. Van Straten, Sorption isotherms, GAB parameters and isosteric heat of sorption, J. Sci. Food Agric. 85 (2005) 1805-1814.

[36] P.N.T. Johnson, J.G. Brennan, Moisture sorption isotherm characteristics of plantain (Musa, AAB), J. Food Eng. 44 (2000) 79-84.

[37] H.A. Iglesias, J. Chirife, P. Viollaz, Thermodynamics of water vapour sorption by sugar beet root, Int. J. Food Sci. Technol. 11 (1976) 91-101.

[38] C. Van den Berg, Description of water activity of foods for engineering purposes by means of the GAB model of sorption, in: B.M. Mc Kenna (Ed.), Engineering and Food, Elsevier Applied Science, New York, 1984, pp. 311-321.

[39] P. Westgate, J.Y. Lee, M.R. Ladisch, Modeling of equilibrium sorption of water vapor on starch materials, Trans. ASAE 35 (1992) 213-219.

[40] F. Kaymak-Ertekin, A. Gedik, Sorption isotherms and isosteric heat of sorption for grapes apricots, apples and potatoes, LWT - Food Sci. Technol. 37 (2004) 429-438.

[41] J.C. Spada, C.P.Z. Noreña, L.D.F. Marczak, I.C. Tessaro, Water adsorption isotherms of microcapsules with hydrolyzed pinhão (Araucaria angustifolia seeds) starch as wall material, J. Food Eng. 114 (2013) 64-69.

[42] Q. Xiao, Q. Tong, Thermodynamic properties of moisture sorption in pullulan-sodium alginate based edible films, Food Res. Int. 54 (2013) 1605-1612.

[43] C.I. Beristain, H.S. Garcia, E. Azuara, Enthalpy-entropy compensation in food vapor adsorption, J. Food Eng. 30 (1996) 405-415.

[44] W.A.M. McMinn, A.H. Al-Muhtaseb, T.R.A. Magee, Enthalpy-entropy compensation in sorption phenomena of starch materials, Food Res. Int. 38 (2005) 505-510.

[45] J.E. Leffler, The enthalpy-entropy relationshipg and its implications for organic chemistry, J. Organ. Chem. 20 (1955) 1202-1231. 